\title{
Ventilator-induced lung injury
}

\author{
J-D. Ricard*,\#, D. Dreyfuss*,\#, G. Saumon*
}

Ventilator-induced lung injury. J-D. Ricard, D. Dreyfuss, G. Saumon. C) ERS Journals Ltd 2003.

ABSTRACT: During mechanical ventilation, high end-inspiratory lung volume (whether it be because of large tidal volume $(V T)$ and/or high levels of positive end-expiratory pressure) results in a permeability type pulmonary oedema, called ventilator-induced lung injury (VILI). Previous injury sensitises lung to mechanical ventilation.

This experimental concept has recently received a resounding clinical illustration after a $22 \%$ reduction of mortality was observed in acute respiratory distress syndrome patients whose $V \mathrm{~T}$ had been reduced. In addition, it has been suggested that repetitive opening and closing of distal units at low lung volume could induce lung injury but this notion has been challenged both conceptually and clinically after the negative results of the Acute Respiratory Distress Syndrome clinical Network Assessment of Low tidal Volume and Elevated end-expiratory volume to Obviate Lung Injury (ARDSNet ALVEOLI) study.

Experimentally and clinically, involvement of inflammatory cytokines in VILI has not been unequivocally demonstrated. Cellular response to mechanical stretch has been increasingly investigated, both on the epithelial and the endothelial side. Lipid membrane trafficking has been thought to be a means by which cells respond to stress failure.

Alterations in the respiratory system pressure/volume curve during ventilator-induced lung injury that include decrease in compliance and position of the upper inflection point are due to distal obstruction of airways that reduce aerated lung volume. Information from this curve could help avoid potentially harmful excessive tidal volume reduction. Eur Respir J 2003; 22: Suppl. 42, 2s-9s.
*Equipe d'Accueil 3512, Institut Fédératif de Recherche 02, Faculté de Médecine Xavier Bichat, Paris, "\#ervice de Réanimation Médicale, Hôpital Louis Mourier, Colombes, France.

Correspondence: J-D. Ricard

Service de Réanimation Médicale

Hôpital Louis Mourier

92700 Colombes

France

Fax: 33147606192

E-mail: jean-damien.ricard@lmr.ap-hop-paris.fr

Keywords: Acute respiratory distress syndrome cytokines

inflammation

mechanical ventilation

ventilator-induced lung injury
Mechanical ventilation has been part of basic life support for several decades. Several potential drawbacks and complications have been identified early in the use of mechanical ventilation [1]. Of these, ventilator-induced lung injury (VILI) has recently received much attention in both the experimental [2] and the clinical field [3-7]. The purpose of this paper is to review the different situations in which VILI can occur based on animal studies and to place these results into a clinical perspective of ventilatory management of acute respiratory distress syndrome (ARDS).

\section{Evidence for ventilator-induced lung injury}

\section{Ventilation of intact lungs}

High lung volume ventilator-induced lung injury. WEBB and TIERNEY [8] were the first to demonstrate that mechanical ventilation could cause pulmonary oedema in intact animals. They were able to show in rats subjected to positive airway pressure ventilation that pulmonary oedema was more severe and occurred more rapidly when the animals were ventilated with $45 \mathrm{cmH}_{2} \mathrm{O}$ than with $30 \mathrm{cmH}_{2} \mathrm{O}$ peak airway pressure. Animals ventilated for $1 \mathrm{~h}$ with $14 \mathrm{cmH}_{2} \mathrm{O}$ peak airway pressure did not develop oedema. It was later confirmed that ventilation with high airway pressure produces capillary permeability alterations, nonhydrostatic pulmonary oedema and tissue damage resembling that observed during ARDS [9]. Further studies demonstrated that VILI depended mainly on lung volume and especially on the end-inspiratory volume [10] The corresponding pressure is termed "plateau" pressure and its clinical importance has been emphasised in a Consensus Conference on mechanical ventilation [11]. The respective roles of increased airway pressure and increased lung volume on the development of VILI were clarified by showing that mechanical ventilation of intact rats with large or low tidal volume $(V \mathrm{~T})$, but with identical peak airway pressures $\left(45 \mathrm{cmH}_{2} \mathrm{O}\right)$ [10] did not result in the same lung alterations. Pulmonary oedema and cellular ultrastructural abnormalities were encountered only in rats subjected to high $V_{\mathrm{T}}$ and not in those in which lung distention was limited by thoracoabdominal strapping [10]. Furthermore, animals ventilated with large $V \mathrm{~T}$ but negative airway pressure (by means of an iron lung) still developed pulmonary oedema thus demonstrating that airway pressure is not a determinant for pulmonary oedema [10]. Consequently, it was suggested that the term "volutrauma" would be more appropriate than barotrauma in this situation $[12,13]$. Other investigators have reached the same conclusions with different protocols and species. HernANDEZ et al. [14] compared the capillary filtration coefficient (a measure of capillary permeability) of the lungs of rabbits ventilated with 15,30 and $45 \mathrm{cmH}_{2} \mathrm{O}$ peak airway pressures with that of animals ventilated with the same airway pressures but with limitation of thoraco-abdominal excursions by plaster casts placed around the chest and the abdomen. The capillary filtration coefficient of the lungs removed after ventilation was normal in animals ventilated at $15 \mathrm{cmH}_{2} \mathrm{O}$ peak pressure, increased by $31 \%$ at $30 \mathrm{cmH}_{2} \mathrm{O}$ peak 
pressure and by $430 \%$ at $45 \mathrm{cmH}_{2} \mathrm{O}$ peak pressure in animals without restriction of lung distention. In striking contrast, limiting lung inflation prevented the increase of the capillary filtration coefficient [14]. CARLTON et al. [15] confirmed this observation in lambs. Besides the lung distention that occurs during mechanical ventilation, the rate at which lung volume varies may also affect microvascular permeability. PEEVY et al. [16] used isolated perfused rabbit lungs to determine the capillary filtration coefficient of lungs ventilated with various $V \mathrm{~T}$ and inspiratory flow rates. They found that small $V \mathrm{~T}$ with a high flow rate increased the filtration coefficient to the same extent ( $\sim 6$ times baseline value) as ventilation with a markedly higher $V \mathrm{~T}$ but a lower inspiratory flow rate for the same peak airway pressure [16].

Taken together, these experimental studies have demonstrated that large volume rather than high intrathoracic pressures per se results in ventilator-induced lung oedema in intact animals.

Low lung volume ventilator-induced lung injury. Unlike high volume lung injury (which can be observed in noninjured animals), low lung volume injury is not seen in healthy lungs, which can tolerate mechanical ventilation with physiological $V \mathrm{~T}$ and low levels of positive end-expiratory pressure (PEEP) for prolonged periods of time without any apparent damage. TASKAR et al. [17] have shown that the repetitive collapse and reopening of terminal units during $1 \mathrm{~h}$ does not seem to damage healthy lungs (although it does alter gas exchange and reduces compliance).

\section{Ventilation of damaged lungs}

High-volume lung injury. Several investigators have evaluated the effect of mechanical ventilation with over-distension on damaged lungs. Results from these studies consistently stress the increased susceptibility of diseased lungs to the detrimental effects of mechanical ventilation.

The first studies were performed on isolated lungs. BOWTON and Kong [18] showed that isolated perfused rabbit lungs injured by oleic acid gained significantly more weight when ventilated with $18 \mathrm{~mL} \cdot \mathrm{kg}^{-1}$ body weight (bw) than when ventilated with $6 \mathrm{~mL} \cdot \mathrm{kg}^{-1}$ bw $V \mathrm{~T}$. HERNANDEZ et al. [19] compared the effects of oleic acid alone, mechanical ventilation alone, and a combination of both on the capillary filtration coefficient and wet-to-dry weight ratio of isolated perfused lungs from young rabbits. These measurements were not significantly affected by low doses of oleic acid, or mechanical ventilation with a peak inspiratory pressure of $25 \mathrm{cmH}_{2} \mathrm{O}$ for $15 \mathrm{~min}$. However, the filtration coefficient increased significantly when oleic acid injury was followed by mechanical ventilation. The wet-to-dry weight ratio (a marker of oedema severity) of these lungs was significantly higher than that of the lungs subjected to oleic acid injury or ventilation alone. The same workers also showed that the increased filtration coefficient produced by ventilating isolated blood-perfused rabbit lungs with $30-45 \mathrm{cmH}_{2} \mathrm{O}$ peak pressure was greater when surfactant was inactivated by instilling dioctyl-succinate [20]. Whereas light microscope examination showed only minor abnormalities (minimal haemorrhage and vascular congestion) in the lungs of animals subjected to ventilation alone, or surfactant inactivation alone, the combination of the two caused severe damage (oedema and flooding, hyaline membranes and extensive alveolar haemorrhage).

These results on isolated lungs suggested that VILI might develop at lower airway pressure in abnormal isolated lungs. Whether this could also be the case in whole animals with "pre-injured lungs" was investigated by comparing the effects of different degrees of lung distention during mechanical ventilation in rats whose lungs had been injured by $\alpha$ naphtylthiourea (ANTU) [21]. ANTU infusion alone caused moderate interstitial pulmonary oedema of the permeability type. Mechanical ventilation of intact rats for 2 min resulted in a permeability oedema whose severity depended on the $V \mathrm{~T}$ amplitude. It was possible to calculate how much mechanical ventilation would theoretically injure lungs diseased by ANTU by summing up the separate effect of mechanical ventilation alone or ANTU alone on oedema severity. The results showed that the lungs of the animals injured by ANTU ventilated at high volume $\left(45 \mathrm{~mL} \cdot \mathrm{kg}^{-1} \mathrm{bw}\right)$ had more severe permeability oedema than predicted, indicating synergism between the two insults rather than additivity. Even minor alterations, such as those produced by spontaneous ventilation during prolonged anaesthesia (which degrades surfactant activity and promotes focal atelectasis [22, 23]), are sufficient to synergistically increase the harmful effects of high volume ventilation [21]. The extent to which lung mechanical properties have deteriorated prior to ventilation is a key factor in this synergy. The amount of oedema produced by high volume mechanical ventilation in the lungs of animals given ANTU, or that had undergone prolonged anaesthesia was inversely proportional to the respiratory system compliance measured at the very beginning of mechanical ventilation [21]. Thus, the more severe the existing lung abnormalities before ventilation, the more severe the VILI. The reason for this synergy requires clarification. The presence of local alveolar flooding in animals given the most harmful ventilation protocol was the most evident difference from those ventilated with lower, less harmful, VT [21]. It is conceivable that flooding reduced the number of alveoli that received the $V \mathrm{~T}$, exposing them to over-inflation and rendering them more susceptible to injury, further reducing the aerated lung volume and resulting in positive feedback. The same reasoning applies to prolonged anaesthesia, during which the aerated lung volume was probably gradually reduced by atelectasis [21]. Both flooding and atelectasis decrease compliance, likely to an extent that is correlated with their spreading. It is thus not surprising that the lower the lung distensibility before ventilation (as inversely reflected by quasi-static compliance, an index of the amount of lung that remains open), the more severe the alterations induced by high volume ventilation [21]. Thus, uneven distribution of ventilation that occurs during acute lung injury [24] may render lungs more prone to regional over-inflation and injury. To explore this possibility, alveolar flooding was produced by instilling $2 \mathrm{~mL}$ saline into the trachea. The rats were then immediately ventilated for $10 \mathrm{~min}$ with $V \mathrm{~T}$ of up to $33 \mathrm{~mL} \cdot \mathrm{kg}^{-1}$. Flooding with saline did not significantly affect microvascular permeability when $V \mathrm{~T}$ was low. As $V \mathrm{~T}$ was increased, capillary permeability alterations were larger in flooded than in intact animals, reflecting further impairment of their endothelial barrier. There was also a correlation between end-inspiratory airway pressure, the pressure at which the lower inflection point (LIP) was found on the pressure/volume $(P / V)$ curve, and capillary permeability alterations in flooded animals ventilated with a high $V \mathrm{~T}$ [25]. Thus, the less compliant and recruitable the lung was after saline flooding, the more severe were the changes in permeability caused by lung distention.

Low lung-volume injury. There may be an increase in trapped gas volume during pulmonary oedema and acute lung injury, especially when surfactant properties are altered, because of terminal units closure [26]. Under such conditions, the slope of the inspiratory $P / V$ curve of the respiratory system often 
displays an abrupt increase at low lung volume. This change reflects the massive opening of previously closed units and has been termed the "lower inflection point" (LIP). Most clinicians are aware of the importance of this phenomenon in terms of arterial oxygenation, since setting PEEP above this inflection point usually results in a very abrupt decrease in shunt and increase in arterial oxygen tension $\left(\mathrm{Pa}_{2} \mathrm{O}_{2}\right)$ [27-30].

Attention has focused only relatively recently on the possibility that pulmonary lesions may be aggravated if this inflection point lies within the $V \mathrm{~T}$. Experimental evidence for this was initially provided by studies comparing conventional mechanical ventilation with high frequency oscillatory ventilation in premature or surfactant-depleted lungs. More recently, studies performed during conventional mechanical ventilation of surfactant-depleted lungs with various levels of PEEP also support the possibility that the repeated opening and closing of terminal units cause additional injury [31-33]. ARGIRAS et al. [31] and SANDHAR et al. [32] studied this issue by ventilating rabbits whose lungs were depleted of surfactant by lavage. Peak inspiratory pressure was $15 \mathrm{mmHg}$ at the beginning of the experiment and $25 \mathrm{mmHg}$ at the end $(5 \mathrm{~h}$ later), because lung compliance decreased ( $V \mathrm{~T}$ was set but not stated). PEEP was adjusted so that functional residual capacity (FRC) was either above or below the LIP on the inspiratory limb of the $P / V$ curve. This resulted in PEEP levels of about 1-2 $\mathrm{mmHg}$ (below inflection) and $8-12 \mathrm{mmHg}$ (above inflection). The mortality rates in the two groups were identical, but the arterial $\mathrm{Pa}, \mathrm{O}_{2}$ was better preserved and there was less hyaline membrane formation in the high PEEP group [31, 32]. This lessening of pathological alterations occurred even when the mean airway pressures in the low and high PEEP groups were kept at the same level by adjusting the inspiratory/ expiratory time ratio [32]. MusCEDERE et al. [33] recently reported similar results for isolated, unperfused, lavaged rabbit lungs ventilated with a low $\left(5-6 \mathrm{~mL} \cdot \mathrm{kg}^{-1} \mathrm{bw}\right) V \mathrm{~T}$ and with a PEEP set below or above the inflection point. However, SoHMA et al. [34] could not replicate these findings in rabbits with hydrochloric acid-injured lungs using the same ventilation settings. The reality of the repetitive opening and closure of terminal units and the significance of the LIP on the $P / V$ curve have been recently challenged by MARTYNOWICZ et al. [35]. They studied the regional expansion of oleic acid-injured lungs using the parenchymal marker technique. They found that the gravitational distribution of volume at the FRC was not affected by oleic acid injury and that the injury was not associated with decreased parenchymal volume of dependent regions. In addition, they found that the temporal inhomogeneity of regional tidal expansion did not increase with oleic acid injury. Their findings are therefore in contradiction with the hypothesis that a gravitational gradient in superimposed pressure during VILI produces compression atelectasis of dependent lung that in turn produces shear injury from cyclic recruitment and collapse [35]. They propose a different explanation for the occurrence of a LIP on the $P / V$ curve, namely the displacement of air-liquid interfaces along the tracheo-bronchial tree rather than alveolar recruitment and derecruitment and thus a different mechanism by which PEEP restores the regional tidal expansion of dependent regions and conclude that the knee in the $P / V$ curve is the result of the mechanics of parenchyma with constant surface tension and partially fluid-filled alveoli, not the result of abrupt opening of airways or atelectatic parenchyma [36]. It therefore remains unsettled whether injury caused by the repetitive reopening of collapsed terminal units and the protective effect of PEEP is restricted to the peculiar situation of surfactant depletion. In the clinical field, the recent negative results of the Acute Respiratory Distress Syndrome clinical Network Assessment of Low tidal Volume and Elevated end-expiratory volume to Obviate Lung Injury (ARDSNet ALVEOLI) trial [37] cast doubt on the clinical existence of repetitive opening and closing lung injury [38].

\section{Roles of tidal volume, positive end-expiratory pressure, and overall lung distention}

The influence of PEEP on acute lung injury (and more specifically on ventilator-induced pulmonary oedema) must be studied with respect to the level of $V$ T used. Indeed, PEEP increases FRC and opens the lung but also displaces endinspiratory volume towards total lung capacity when $V \mathrm{~T}$ is kept constant possibly thus favouring over-inflation. PEEP may also affect haemodynamics and lung fluid balance. Therefore, close analysis of the numerous studies which have been carried out to clarify the relationships between PEEP, oxygenation, and the accumulation of extravascular lung water during hydrostatic or permeability type oedema must take into account the experimental approach used, i.e. intact animals or isolated lungs (for which lung water content will differ) and whether or not $V \mathrm{~T}$ is reduced (thus increasing or not increasing end-inspiratory lung volume).

\section{Effects of positive end-expiratory pressure when tidal volume is kept constant}

Application of PEEP may result in lung over-inflation if it is followed by a significant change in FRC owing to the increase in end-inspiratory volume. Depending on the homogeneity of ventilation distribution, this over-inflation will preferentially affect the more distensible areas, thus accounting for the usual lack of reduction or even the worsening of oedema reported with PEEP during most experiments [39]. In intact animals, application of PEEP does not counteract the accumulation of oedema fluid during hydrostatic type oedema [40] or permeability type oedema [40, 41], though it improves oxygenation [40] because of the re-opening of flooded alveoli. In isolated ventilated-perfused lung, PEEP aggravates oedema fluid accumulation [42]. Thus, for a given $V \mathrm{~T}$, increasing $\mathrm{FRC}$ with PEEP has dissimilar effects on oedema accumulation in isolated lungs and in intact animals. In the latter, the lack of effect of PEEP depends on the balance between PEEPinduced increase in end-inspiratory lung volume which decreases interstitial pressure and favours fluid filtration in extra-alveolar vessels and the haemodynamic depression due to elevated intrathoracic pressure that will decrease filtration pressure. In contrast, the preservation of perfusion-rate in isolated-perfused lungs favours the increase in oedema [42].

\section{Effects of positive-end expiratory pressure when tidal volume is reduced}

Oedema is less severe when $V \mathrm{~T}$ is decreased and endinspiratory lung volume is kept constant by increasing FRC with PEEP during high-volume ventilation [2]. WEBB and TIERNEY [8] showed that oedema was lessened by $10 \mathrm{cmH}_{2} \mathrm{O}$ PEEP application during ventilation with $45 \mathrm{cmH}_{2} \mathrm{O}$ peak airway pressure. The authors attributed this beneficial effect of PEEP to the preservation of surfactant activity. It was shown later that although PEEP decreased the amount of oedema, it did not change the severity of the permeability alterations as assessed by the increase in dry lung weight [10]. However, no alveolar damage was observed in animals ventilated with PEEP in comparison with those ventilated in zero end-expiratory pressure (ZEEP). The only ultrastructural alterations observed with PEEP consisted of endothelial 
blebbing [10]. This preservation of the epithelial layer has received no satisfactory explanation. It may be that PEEP prevented repetitive opening and closing of terminal units, thereby decreasing shear stress at this level. Similar observations have been made by other investigators either in intact animals [43, 44] or in perfused canine lobes [45]. The potential role of haemodynamic alterations induced by PEEP should be considered. For a given end-inspiratory airway pressure, application of PEEP produces an increase in intrathoracic pressure which adversely affects cardiac output [46, 47]. Indeed, rats submitted to high-peak airway pressure ventilation with $10 \mathrm{cmH}_{2} \mathrm{O}$ PEEP had more severe oedema when the haemodynamic alterations induced by PEEP were corrected with dopamine [48]. The amount of oedema was correlated with systemic blood pressure, suggesting that improvement in cardiac output and increased filtration were responsible for this aggravation. In conclusion, the reduction of oedema and of the severity of cell damage by PEEP during ventilationinduced pulmonary oedema may be linked to reduced tissue stress (by decreasing volume-pressure excursion) and capillary filtration, as well as to the preservation of surfactant activity.

\section{Importance of overall lung distention}

Lung volume at the end of inspiration (i.e. the overall degree of lung distention) is probably the main determinant of VILI severity. Rats ventilated with a low $V \mathrm{~T}$ and $15 \mathrm{cmH}_{2} \mathrm{O}$ PEEP developed pulmonary oedema whereas rats ventilated with the same $V$ T but $10 \mathrm{cmH}_{2} \mathrm{O}$ PEEP did not [48]. Similarly, doubling $V$ T (which was not deleterious in animals ventilated in ZEEP) resulted in oedema in the presence of $10 \mathrm{cmH}_{2} \mathrm{O}$ PEEP. Thus the safety of a given $V$ T depends on how much FRC is increased.

In conclusion, VILI and oedema occurs when a certain degree of lung overinflation is reached. This situation is met when $V \mathrm{~T}$ is increased at a given end-inspiratory pressure. By contrast, when PEEP is added to reach the same endinspiratory pressure, it seems to slow the development of oedema and diminish the severity of tissue injury, although the occurrence of microvascular permeability alterations is not prevented [10, 48]. Finally, when PEEP results in additional over-inflation, there is greater oedema [48].

\section{Possible mechanisms of ventilator-induced lung injury}

It is now clear that ventilation-induced pulmonary oedema is essentially the result of severe changes in the permeability of the alveolar-capillary barrier. Small increases in microvascular transmural pressure may add their effects to those of altered permeability to enhance oedema severity.

Depending on the duration of the aggression, two different kinds of injury probably occur. Small animals very rapidly develop a severe permeability pulmonary oedema as a consequence of acute extreme lung stretching. This oedema probably does not involve inflammatory cell recruitment or secretion of mediators. Oedema develops more slowly in larger animals, in particular in response to moderately high airway pressures, rendering the situation more complex. A low lung volume injury probably adds its own effects to the direct mechanical aggression at high end-inspiratory volume. Indeed, high $V \mathrm{~T}$ mechanical ventilation without PEEP may reduce the aerated volume and gradually cause mechanical nonuniformity. This lung inhomogeneity will in turn promote over-inflation of the more distensible and probably healthier zones, leading to positive feedback aggravation. In addition, lung injury develops slowly enough in large animals for inflammatory pathways to become involved.

\section{Mechanisms of increased vascular transmural pressure}

Increased fluid filtration by this mechanism may occur at both extra-alveolar [49, 50] and alveolar [51-53] sites during mechanical ventilation. Increased transmural pressure in extraalveolar vessels may result from the increase in lung volume, a consequence of lung interdependence [46, 54, 55], whereas increased filtration across alveolar microvessels may be the consequence of surfactant inactivation $[8,53]$.

\section{Mechanisms of altered permeability}

While permeability alterations are obvious and severe during ventilator-induced oedema, the underlying mechanisms are not fully understood, and there are probably several. In particular, as previously stressed, the mechanisms of lung injury may well vary according to the extent and duration of lung overdistension.

Effects of surfactant inactivation. In addition to its effects on fluid filtration, surfactant inactivation and elevated alveolar surface tension may increase alveolar epithelial permeability to small solutes. Diethylenetriaminepentaacetic acid (DTPA) clearance in rabbits [56] and dogs [57] was increased following surfactant inactivation by detergent aerosolisation. This effect was ascribed to the uneven distribution of lung mechanical properties resulting in ventilation inhomogeneities and regional overexpansion, rather than to the elimination of peculiar barrier properties of surfactant [57]. The effects of surfactant inactivation and large $V \mathrm{~T}$ ventilation on alveolocapillar permeability (as assessed by pulmonary DTPA clearance) are additive [58]. Increased surface tension may also alter endothelial permeability as a result of increased radial traction on pulmonary microvessels [53].

Participation of inflammatory cells and mediators. Role of inflammatory cells. The endothelial cell disruptions that have been observed during over-inflation oedema in small animals may allow direct contact between polymorphonuclear cells and basement membrane. This contact may promote leukocyte activation. As previously mentioned, the short duration of experiments conducted in small animals did not allow massive leukocyte recruitment. A striking feature of the VILI that occurs after several hours in larger animals is the infiltration of inflammatory cells into the interstitial and alveolar spaces. In one of the earliest studies on this subject, Woo and HedLEY-white [59] observed that overinflation produced oedema in open-chest dogs, and that leukocytes accumulated in the vasculature and macrophages in the alveoli. Further studies have confirmed these results [60] and shown that high transpulmonary pressure increased the transit time of leukocytes in the lungs of rabbits [61]. Conversely, when animals are depleted in neutrophils, high volume pulmonary oedema is less severe than in nondepleted animals [62].

Role of inflammatory mediators. The participation of inflammatory cytokines in the course of VILI has been the subject of recent studies and is a matter of debate [63]. Tremblay et al. [64] examined the effects of different ventilatory strategies on the level of several cytokines in bronchoalveolar lavage fluid of isolated rat lungs ventilated with different end-expiratory pressures and $V \mathrm{~T}$. High $V \mathrm{~T}$ 
ventilation $\left(40 \mathrm{~mL} \cdot \mathrm{kg}^{-1}\right.$ bw) with ZEEP resulted in considerable increases in tumour necrosis factor (TNF)- $\alpha$, interleukin (IL)-1B and IL-6 and in macrophage inflammatory protein (MIP)-2 (a potent neutrophil chemoattractant and the rodent functional homologue of human IL-8). Unfortunately, results from this study have not been replicated by another group using the same ex vivo lung model [65]. It is worth noting that stretching in vitro human alveolar macrophages [66] or A549 epithelial cells [67] did not lead to TNF- $\alpha$ release, but did result in the release of IL-8. In vivo studies of intact animals show that high volume mechanical ventilation that produces a very severe pulmonary oedema does not induce the release of TNF- $\alpha[65,68]$. Studies on TNF- $\alpha$ messenger ribonucleic acid (mRNA) also yield conflicting results since TAKATA et al. [69] showed large increases in TNF- $\alpha$ mRNA in the intra-alveolar cells of surfactant-depleted rabbits after $1 \mathrm{~h}$ of conventional mechanical ventilation with peak inspiratory and end-expiratory pressures of 28 and $5 \mathrm{cmH}_{2} \mathrm{O}$ (resulting in a mean airway pressure of $13 \mathrm{cmH}_{2} \mathrm{O}$ ) whereas in the study by IMANAKA et al. [70] there was no increase in lung tissue TNF- $\alpha$ mRNA of rats ventilated by high pressure $\left(45 \mathrm{cmH}_{2} \mathrm{O}\right.$ of peak inspiratory pressure).

The only mediator which is constantly found in the different experimental studies is MIP-2 (or IL-8, depending on the experimental model). The presence of this neutrophil chemoattractant mediator in lungs subjected to high volume ventilation is in agreement with the well documented recruitment of neutrophils that occurs after long-term ventilation [60, 71-73].

In addition to increasing the amount of cytokines in the lung, it has been suspected that over-inflation during mechanical ventilation may promote the release of cytokines [74, 75] or bacteria $[76,77]$ into the blood, thus giving a causative role for mechanical ventilation in multi-organ dysfunction [78, 79]. However, this hypothesis remains to be proven [80].

\section{New insights in ventilator-induced lung injury: cellular response to mechanical strain}

Growing interest has focused on the cellular response to mechanical strain and have been comprehensively reviewed lately [81]. PARKER et al. [82] studied the different signal transduction pathways that may be involved in the microvascular permeability increases observed during experimental VILI. They found that gadolinium (that blocks stretchactivated nonselective cation channels) annulled the increases in vascular permeability induced by high airway pressure [83]. The authors concluded that stretch-activated cation channels might initiate the increase in permeability induced by mechanical ventilation through increases in intracellular calcium ion $\left(\mathrm{Ca}^{2+}\right)$ concentration. To further explore this hypothesis, the same team studied the effect of inhibitors of the $\mathrm{Ca}^{2+}$ / calmodulin-myosin light chain kinase pathway on vascular permeability [84]. Using an isolated perfused rat model, they showed that kinase inhibitors, which may prevent $\mathrm{Ca}^{2+}$ entry, contraction of the actin-myosin filaments or release of adhesion proteins, could significantly attenuate the vascular permeability increase induced by high pressure mechanical ventilation [84]. Taken together, these results suggest that the increase in microvascular permeability may not be a simply passive physical phenomenon (a "stress failure" $[85,86]$ ), but the result of biochemical reactions. Maintenance of plasma membrane integrity is essential in response to mechanical stress. Recently, VLAHAKIS et al. [87] reported a previously undescribed response of alveolar epithelial cells to deformation. They labelled membrane lipids to study deformation-induced lipid trafficking and observed in a direct manner (laser confocal microscopy) the response of epithelial cells of the alveolar basement membrane to deforming forces. A $25 \%$ stretch deformation resulted in lipid transport to the plasma membrane to ensure its integrity and an increase in epithelial cell surface area. This lipid trafficking occurred in all cells, in contrast with plasma breaks which were seen in only a small percentage of cells. The authors concluded that deformationinduced lipid trafficking serves, in part, to repair plasma breaks in order to maintain plasma membrane integrity and cell viability, and that this could be viewed as a cytoprotective mechanism against plasma membrane stress failure seen during VILI [10, 86]. Other investigators have focused on the relative importance of deformation frequency, duration, and amplitude in deformation-induced cell injury [88]. Exposing rat primary alveolar epithelial cells to cyclic deformation $(25,37$ and $60 \%$ increase in membrane surface area $(\Delta \mathrm{SA}))$ led to significantly greater cell death in comparison with static deformation. To investigate the relative importance of peak deformation magnitude, a cyclic deformation amplitude on deformation-induced injury, cells were submitted to cyclic deformation amplitudes of $12 \%$ and $25 \% \Delta$ SA superimposed on a static deformation of $25 \% \Delta \mathrm{SA}$, thus resulting in a peak deformation magnitude of 37 and $50 \% \Delta \mathrm{SA}$, respectively. Interestingly, authors found that limiting the deformation amplitude resulted in significant reductions in cell death at identical peak deformations. From these results, an analogy can be drawn with experiments that showed a decrease in lung injury when $V$ T was reduced with a constant PEEP level, thus reducing end-inspiratory lung volume [48].

\section{Strategies to reduce ventilator-induced lung injury: use of the pressure/volume curve}

The ARDS network trial [6] has undisputedly shown that reducing $V$ T from $12 \mathrm{~mL} \cdot \mathrm{kg}^{-1}$ to $6 \mathrm{~mL} \cdot \mathrm{kg}^{-1}$ resulted in a $22 \%$ reduction of mortality. Due to protocol, the same reduction of $V \mathrm{~T}$ was applied in all the patients allocated to the low $V \mathrm{~T}$ group. However, it has repeatedly been shown that the pressure and the volume that are considered safe for some ARDS patients may cause lung overdistension in others [89-92]. Conversely, arbitrary settings may result in an unnecessary reduction in $V \mathrm{~T}$, which a recent meta-analysis has suggested as being potentially harmful [7]. It has been suggested that information from the inspiratory $P / V$ curve of the respiratory system could be used to tailor ventilator settings. For instance, the presence of an opening pressure (LIP) could be used to adjust the PEEP [27-29]. In addition to improving oxygenation, PEEP reduces the severity of VILI [10] and may lessen the damage produced by the repeated opening and closing of lung units in surfactant-depleted lungs $[31,33]$. However, PEEP may favour over-inflation if $V \mathrm{~T}$ is not reduced $[2,93]$. It has been proposed that the $V \mathrm{~T}$ be adjusted according to $P / V$ curve analysis by limiting endinspiratory pressures to below the decrease in slope seen at high $P / V$, called the upper inflection point (UIP) [3, 91, 92]. The UIP often seen in patients with ARDS has been ascribed to over-inflation [91, 92], or to the end of recruitment [94, 95] during lung expansion. However, whether or not ventilator settings that would result in $P / V$ excursions above the UIP are deleterious remains undecided, and has never been assessed experimentally. The impact of pulmonary oedema and the resulting decrease in ventilatable lung volume on the inspiratory limb of the respiratory system $P / V$ curve has not yet been evaluated. A better understanding of its significance is required before the UIP can be used to set $V \mathrm{~T}$ in patients. A recent experimental study was designed to examine several hypotheses [96]. The first was that, the reduction in ventilatable lung volume (the baby-lung effect) not only decreases the 
compliance of the lung $[89,97]$ but also affects the position of the UIP. The second was that the development of oedema alters the $P / V$ curve essentially because of distal airway obstruction. And the third was that individual characteristics of the $P / V$ curve reflect the susceptibility of the lungs to the deleterious effects of high volume ventilation. The first two hypotheses were tested by obstructing the distal airways of rats by instilling a viscous liquid and by comparing the $P / V$ curves obtained to those obtained during hyper-inflation ventilation of intact rats. The authors found that changes in the shape of the $P / V$ curve (gradual decrease in compliance and volume at which the UIP was seen, and progressive in end-inspiratory pressure) were very similar whether they were due to viscous instillation into the lungs or due to the development of overdistension pulmonary oedema. To test the third hypothesis, $P / V$ curves prior to mechanical overinflation were examined with respect to the amount of pulmonary oedema induced by over-inflation in lungs injured by ANTU. The authors found that the higher the compliance and the position of the UIP before over-inflation, the less oedema occurred after over-inflation. Taken together, these results suggest that the position of the UIP is a marker of ventilatable lung volume and is both influenced by and predictive of the development of oedema during mechanical ventilation.

\section{Conclusion and clinical applications}

The experimental concept of VILI has recently received a resounding clinical relevance [6]. However, what might have been seen as the final step in ARDS ventilatory strategy knowledge (i.e. unilateral drastic $V \mathrm{~T}$ reduction for every ARDS patient) has very recently been shaken [7]. For the time being and until further evidence, one may put forward the following conclusions: 1) drastic $V \mathrm{~T}$ reduction may not be justified for every ARDS patient; 2) reasoned $V \mathrm{~T}$ reduction, designed to avoid volutrauma, may be guided by the state of lung mechanical properties as can be provided by the respiratory system $P / V$ curve, in order to avoid excessive or insufficient VT reduction; and 3) use of high levels of PEEP is not to date justified.

Evidence-based ventilatory management of adult respiratory distress syndrome is a difficult art, luckily basic physiology is still there to help clinicians [38, 63, 98, 99].

\section{References}

1. Pingleton SK. Complications of acute respiratory failure. Am Rev Respir Dis 1988; 137: 1463-1493.

2. Dreyfuss D, Saumon G. Ventilator-induced lung injury: lessons from experimental studies. Am J Respir Crit Care Med 1998; 157: 294-323.

3. Amato MB, Barbas CS, Medeiros DM, et al. Effect of a protective-ventilation strategy on mortality in the acute respiratory distress syndrome. N Engl J Med 1998; 338: 347354.

4. Brochard L, Roudot-Thoraval F, Roupie E, et al. Tidal volume reduction for prevention of ventilator-induced lung injury in acute respiratory distress syndrome. The Multicenter Trail Group on Tidal Volume Reduction in ARDS. Am J Respir Crit Care Med 1998; 158: 1831-1838.

5. Stewart TE, Meade MO, Cook DJ, et al. Evaluation of a ventilation strategy to prevent barotrauma in patients at high risk for acute respiratory distress syndrome. Pressure- and Volume-Limited Ventilation Strategy Group. N Engl J Med 1998; 338: 355-361.

6. The Acute Respiratory Distress Syndrome Network. Ventilation with lower tidal volumes as compared with traditional tidal volumes for acute lung injury and the acute respiratory distress syndrome. N Engl J Med 2000; 342: 1301-1308.

7. Eichacker PQ, Gerstenberger EP, Banks SM, Cui X, Natanson C. A metaanalysis of ALI and ARDS trials testing low tidal volumes. Am J Respir Crit Care Med 2002; 28: 28.

8. Webb HH, Tierney DF. Experimental pulmonary edema due to intermittent positive pressure ventilation with high inflation pressures. Protection by postive end-expiratory pressure. Am Rev Respir Dis 1974; 110: 556-565.

9. Dreyfuss D, Basset G, Soler P, Saumon G. Intermittent positive-pressure hyperventilation with high inflation pressures produces pulmonary microvascular injury in rats. Am Rev Respir Dis 1985; 132: 880-884.

10. Dreyfuss D, Soler P, Basset G, Saumon G. High inflation pressure pulmonary edema. Respective effects of high airway pressure, high tidal volume, and positive end-expiratory pressure. American Review of Respiratory Disease 1988; 137 : $1159-1164$.

11. Slutsky AS. Consensus conference on mechanical ventilation - January 28-30, 1993 at Northbrook, Illinois, USA. Intensive Care Med 1994; 20: 64-79.

12. Dreyfuss D, Saumon G. Barotrauma is volutrauma, but which volume is the one responsible? Intensive Care Medicine 1992; 18: 139-141.

13. Dreyfuss D, Soler P, Saumon G. Spontaneous resolution of pulmonary edema caused by short periods of cyclic overinflation. Journal of Applied Physiology 1992; 72: 20812089.

14. Hernandez LA, Peevy KJ, Moise AA, Parker JC. Chest wall restriction limits high airway pressure-induced lung injury in young rabbits. J Appl Physiol 1989; 66: 2364-2368.

15. Carlton DP, Cummings JJ, Scheerer RG, Poulain FR, Bland RD. Lung overexpansion increases pulmonary microvascular protein permeability in young lambs. $J$ Appl Physiol 1990; 69: 577-583.

16. Peevy KJ, Hernandez LA, Moise AA, Parker JC. Barotrauma and microvascular injury in lungs of nonadult rabbits: effect of ventilation pattern. Crit Care Med 1990; 18: $634-637$.

17. Taskar V, John J, Evander E, Robertson B, Jonson B. Healthy lungs tolerate repetitive collapse and reopening during short periods of mechanical ventilation. Acta Anaesthesiol Scand 1995; 39: 370-376.

18. Bowton DL, Kong DL. High tidal volume ventilation produces increased lung water in oleic acid-injured rabbit lungs. Crit Care Med 1989; 17: 908-911.

19. Hernandez LA, Coker PJ, May S, Thompson AL, Parker JC. Mechanical ventilation increases microvascular permeability in oleic acid-injured lungs. J Appl Physiol 1990; 69: 20572061.

20. Coker PJ, Hernandez LA, Peevy KJ, Adkins K, Parker JC. Increased sensitivity to mechanical ventilation after surfactant inactivation in young rabbit lungs. Crit Care Med 1992; 20: 635-640.

21. Dreyfuss D, Soler P, Saumon G. Mechanical ventilationinduced pulmonary edema. Interaction with previous lung alterations. Am J Respir Crit Care Med 1995; 151: 15681575 .

22. Huang YC, Weinmann GG, Mitzner W. Effect of tidal volume and frequency on the temporal fall in compliance. J Appl Physiol 1988; 65: 2040-2047.

23. Ward HE, Nicholas TE. Effect of artificial ventilation and anaesthesia on surfactant turnover in rats. Respir Physiol 1992; 87: 115-129.

24. Tsang JY, Emery MJ, Hlastala MP. Ventilation inhomogeneity in oleic acid-induced pulmonary edema. $J$ Appl Physiol 1997; 82: 1040-1045.

25. Dreyfuss D, Martin-Lefevre L, Saumon G. Hyperinflationinduced lung injury during alveolar flooding in rats: effect of perfluorocarbon instillation. Am J Respir Crit Care Med 1999; 159: 1752-1757.

26. Hughes JMB, Rosenzweig DY. Factors affecting trapped gas 
volume in perfused dog lungs. J Appl Physiol 1970; 29: 332339.

27. Falke KJ, Pontoppidan H, Kumar A, Leith DE, Geffin B, Laver MB. Ventilation with end-expiratory pressure in acute lung disease. J Clin Invest 1972; 51: 2315-2323.

28. Suter PM, Fairley B, Isenberg MD. Optimum end-expiratory airway pressure in patients with acute pulmonary failure. $N$ Engl J Med 1975; 292: 284-289.

29. Matamis D, Lemaire F, Harf A, Brun-Buisson C, Ansquer JC, Atlan G. Total respiratory pressure-volume curves in the adult respiratory distress syndrome. Chest 1984; 86: 58-66.

30. Benito S, Lemaire F. Pulmonary pressure-volume relationship in acute respiratory distress syndrome in adults: role of positive end-expiratory pressure. J Crit Care 1990; 5: 27-34.

31. Argiras EP, Blakeley CR, Dunnill MS, Otremski S, Sykes MK. High peep decreases hyaline membrane formation in surfactant deficient lungs. Br J Anaesth 1987; 59: 1278-1285.

32. Sandhar BK, Niblett DJ, Argiras EP, Dunnill MS, Sykes MK. Effects of positive end-expiratory pressure on hyaline membrane formation in a rabbit model of the neonatal respiratory distress syndrome. Intensive Care Med 1988; 14: 538-546.

33. Muscedere JG, Mullen JB, Gan K, Slutsky AS. Tidal ventilation at low airway pressures can augment lung injury. Am J Respir Crit Care Med 1994; 149: 1327-1334.

34. Sohma A, Brampton WJ, Dunnill MS, Sykes MK. Effect of ventilation with positive end-expiratory pressure on the development of lung damage in experimental acid aspiration pneumonia in the rabbit. Intensive Care Med 1992; 18: 112117.

35. Martynowicz MA, Minor TA, Walters BJ, Hubmayr RD. Regional expansion of oleic acid-injured lungs. Am J Respir Crit Care Med 1999; 160: 250-258.

36. Wilson TA, Anafi RC, Hubmayr RD. Mechanics of edematous lungs. J Appl Physiol 2001; 90: 2088-2093.

37. ARDSNet ALVEOLI study. http://hedwig.mgh.harvard.edu/ ardsnet/ards04.html. Date updated: 5 May 2003; Date accessed: 2 May 2003.

38. Hubmayr RD. Perspective on lung injury and recruitment: a skeptical look at the opening and collapse story. Am J Respir Crit Care Med 2002; 165: 1647-1653.

39. Rizk NW, Murray JF. PEEP and pulmonary edema. Am J Med 1982; 72: 381-383.

40. Hopewell PC, Murray JF. Effects of continuous positivepressure ventilation in experimental pulmonary edema. J Appl Physiol 1976; 40: 568-574.

41. Luce JM, Huang TW, Robertson HT, et al. The effects of prophylactic expiratory positive airway pressure on the resolution of oleic acid-induced lung injury in dogs. Ann Surg 1983; 197: 327-336.

42. Toung T, Saharia P, Permutt S, Zuidema GD, Cameron JL. Aspiration pneumonia: beneficial and harmful effects of positive end-expiratory pressure. Surgery 1977; 82: 279-283.

43. Corbridge TC, Wood LDH, Crawford GP, Chudoba MJ, Yanos J, Sznadjer JI. Adverse effects of large tidal volume and low PEEP in canine acid aspiration. Am Rev Respir Dis 1990; 142: 311-315.

44. Colmenero Ruiz M, Fernández Mondéjar E, Fernández Sacristán MA, Rivera Fernández R, Vazquez Mata G. PEEP and low tidal volume ventilation reduce lung water in porcine pulmonary edema. Am J Respir Crit Care Med 1997; 155: 964-970.

45. Bshouty Z, Ali J, Younes M. Effect of tidal volume and PEEP on rate of edema formation in in situ perfused canine lobes. J Appl Physiol 1988; 64: 1900-1907.

46. Permutt S. Mechanical influences on water accumulation in the lungs. In: Fishman AP, Renkin EM, eds. Pulmonary Edema. Bethesda, MD, American Physiological Society, 1979; pp. 175-193.

47. Luce JM. The cardiovascular effects of mechanical ventilation and positive end-expiratory pressure. JAMA 1984; 252: 807-811.
48. Dreyfuss D, Saumon G. Role of tidal volume, FRC, and end-inspiratory volume in the development of pulmonary edema following mechanical ventilation. Am Rev Respir Dis 1993; 148: 1194-1203.

49. Iliff LD. Extra-alveolar vessels and edema development in excised dog lungs. Circ Res 1971; 28: 524-532.

50. Albert RK, Lakshminarayan S, Kirk W, Butler J. Lung inflation can cause pulmonary edema in zone I of in situ dog lungs. J Appl Physiol 1980; 49: 815-819.

51. Pattle RE. Properties, function and origin of the alveolar lining layer. Nature (Lond) 1955; 175: 1125-1126.

52. Clements JA. Pulmonary edema and permeability of alveolar membranes. Arch Environ Health 1961; 2: 280-283.

53. Albert RK, Lakshminarayan S, Hildebrandt J, Kirk W, Butler J. Increased surface tension favors pulmonary edema formation in anesthetized dogs' lungs. J Clin Invest 1979; 63: $1015-1018$.

54. Howell JBL, Permutt S, Proctor DF, Riley RL. Effect of inflation of the lung on different parts of pulmonary vascular bed. J Appl Physiol 1961; 16: 71-76.

55. Benjamin JJ, Murtagh PS, Proctor DF, Menkes HA, Permutt S. Pulmonary vascular interdependence in excised dog lobes. J Appl Physiol 1974; 37: 887-894.

56. Jefferies AL, Kawano T, Mori S, Burger R. Effect of increased surface tension and assisted ventilation on $99 \mathrm{mTc}-$ DTPA clearance. J Appl Physiol 1988; 64: 562-568.

57. Nieman G, Ritter-Hrncirik C, Grossman Z, Witanowski L, Clark W, Bredenberg C. High alveolar surface tension increases clearance of technetium $99 \mathrm{~m}$ diethylenetriaminepentaacetic acid. J Thorac Cardiovasc Surg 1990; 100: 129133.

58. John J, Taskar V, Evander E, Wollmer P, Jonson B. Additive nature of distension and surfactant perturbation on alveolocapillary permeability. Eur Respir J 1997; 10: 192-199.

59. Woo SW, Hedley-White J. Macrophage accumulation and pulmonary edema due to thoracotomy and lung overinflation. J Appl Physiol 1972; 33: 14-21.

60. Tsuno K, Miura K, Takeya M, Kolobow T, Morioka T. Histopathologic pulmonary changes from mechanical ventilation at high peak airway pressures. Am Rev Respir Dis 1991; 143: 1115-1120.

61. Markos J, Doerschuk CM, English D, Wiggs BR, Hogg JC. Effect of positive end-expiratory pressure on leukocyte transit in rabbit lungs. $J$ Appl Physiol 1993; 74: 26272633.

62. Kawano T, Mori S, Cybulsky M, et al. Effect of granulocyte depletion in a ventilated surfactant-depleted lung. $J$ Appl Physiol 1987; 62: 27-33.

63. Ricard J-D, Dreyfuss D. Cytokines during ventilatorinduced lung injury: a word of caution. Anesth Analg 2001; 93: $251-252$.

64. Tremblay L, Valenza F, Ribeiro SP, Li J, Slutsky AS. Injurious ventilatory strategies increase cytokines and c-fos m-RNA expression in an isolated rat lung model. $J$ Clin Invest 1997; 99: 944-952.

65. Ricard J-D, Dreyfuss D, Saumon G. Production of inflammatory cytokines during ventilator-induced lung injury: a reappraisal. Am J Respir Crit Care Med 2001; 163: 1176-1180.

66. Pugin J, Dunn I, Jolliet $\mathrm{P}$, et al. Activation of human macrophages by mechanical ventilation in vitro. Am J Physiol 1998; 275: L1040-1050.

67. Vlahakis NE, Schroeder MA, Limper AH, Hubmayr RD. Stretch induces cytokine release by alveolar epithelial cells in vitro. Am J Physiol 1999; 277: L167-L173.

68. Verbrugge SJC, Uhlig S, Neggers SJCM, et al. Different ventilation strategies affect lung function but do not increase tumor necrosis factor- $\alpha$ and prostacyclin production in lavaged rat lungs in vivo. Anesthesiology 1999; 91: 1834 1843.

69. Takata M, Abe J, Tanaka H, et al. Intraalveolar expression of tumor necrosis factor-alpha gene during conventional and 
high-frequency ventilation. Am J Respir Crit Care Med 1997; 156: 272-279.

70. Imanaka H, Shimaoka M, Matsuura N, Nishimura M, Ohta $\mathrm{N}$, Kiyono H. Ventilator-induced lung injury is associated with neutrophil infiltration, macrophage activation, and TGF-ss1 mRNA upregulation in rat lungs. Anesth Analg 2001; 92: 428-436.

71. Matsuoka T, Kawano T, Miyasaka K. Role of highfrequency ventilation in surfactant-depleted lung injury as measured by granulocytes. $J$ Appl Physiol 1994; 76: 539-544.

72. Sugiura M, McCulloch PR, Wren S, Dawson RH, Froese AB. Ventilator pattern influences neutrophil influx and activation in atelectasis-prone rabbit lung. J Appl Physiol 1994; 77: $1355-1365$.

73. Imai $\mathrm{Y}$, Kawano $\mathrm{T}$, Miyasaka $\mathrm{K}$, Takata M, Imai $\mathrm{T}$, Okuyama K. Inflammatory chemical mediators during conventional ventilation and during high frequency oscillatory ventilation. Am J Respir Crit Care Med 1994; 150: 15501554.

74. von Bethmann AN, Brasch F, Nusing R, et al. Hyperventilation induces release of cytokines from perfused mouse lung. Am J Respir Crit Care Med 1998; 157: 263-272.

75. Chiumello D, Pristine G, Slutsky AS. Mechanical ventilation affects local and systemic cytokines in an animal model of acute respiratory syndrome. Am J Respir Crit Care Med 1999; 160: 109-116.

76. Nahum A, Hoyt J, Schmitz L, Moody J, Shapiro R, Marini JJ. Effect of mechanical ventilation strategy on dissemination of intratracheally instilled Escherichia coli in dogs. Crit Care Med 1997; 25: 1733-1743.

77. Verbrugge SJ, Sorm V, van't Veen A, Mouton JW, Gommers D, Lachmann B. Lung overinflation without positive end-expiratory pressure promotes bacteremia after experimental Klebsiella pneumoniae inoculation. Intensive Care Med 1998; 24: 172-177.

78. Slutsky AS, Tremblay LN. Multiple system organ failure. Is mechanical ventilation a contributing factor? Am J Respir Crit Care Med 1998; 157: 1721-1725.

79. Dreyfuss D, Saumon G. From ventilator-induced lung injury to multiple organ dysfunction? Intensive Care Med 1998; 24: 102-104.

80. Pugin $\mathbf{J}$. Is the ventilator responsible for lung and systemic inflammation? Intensive Care Med 2002; 28: 817-819.

81. Dos Santos CC, Slutsky AS. Mechanisms of ventilatorinduced lung injury: a perspective. J Appl Physiol 2000; 89: 1645-1655.

82. Parker JC, Townsley MI, Rippe B, Taylor AE, Thigpen J. Increased microvascular permeability in dog lungs due to high peak airway pressures. J Appl Physiol 1984; 57: 18091816.

83. Parker JC, Ivey CL, Tucker A. Gadolinium prevents high airway pressure-induced permeability increases in isolated rat lungs. J Appl Physiol 1998; 84: 1113-1118.

84. Parker JC. Inhibitors of myosin light chain kinase and phosphodiesterase reduce ventilator-induced lung injury. J Appl Physiol 2000; 89: 2241-2248.
85. West JB, Tsukimoto K, Mathieu Costello M, Prediletto R. Stress failure in pulmonary capillaries. J Appl Physiol 1991; 70: 1731-1742.

86. Fu Z, Costello ML, Tsukimoto K, et al. High lung volume increases stress failure in pulmonary capillaries. $J$ Appl Physiol 1992; 73: 123-133.

87. Vlahakis NE, Schroeder MA, Pagano RE, Hubmayr RD. Deformation-induced lipid trafficking in alveolar epithelial cells. Am J Physiol 2001; 280: L938-L946.

88. Tschumperlin DJ, Oswari J, Margulies SS. Deformationinduced injury of alveolar epithelial cells: effects of frequency, duration and amplitude. Am J Respir Crit Care Med 2000; 162: $357-362$.

89. Gattinoni L, Pesenti A, Avalli L, Rossi F, Bombino M. Pressure-volume curve of total respiratory system in acute respiratory failure. Computed tomographic scan study. Am Rev Respir Dis 1987; 136: 730-736.

90. Gattinoni L, Pelosi P, Crotti S, Valenza F. Effects of positive end-expiratory pressure on regional distribution of tidal volume and recruitment in adult respiratory distress syndrome. Am J Respir Crit Care Med 1995; 151: 18071814.

91. Roupie E, Dambrosio M, Servillo G, et al. Titration of tidal volume and induced hypercapnia in acute respiratory distress syndrome. Am J Respir Crit Care Med 1995; 152: 121-128.

92. Dambrosio M, Roupie E, Mollet JJ, et al. Effects of positive end-expiratory pressure and different tidal volumes on alveolar recruitment and hyperinflation. Anesthesiology 1997; 87: 495-503.

93. Ranieri VM, Mascia L, Fiore T, Bruno F, Brienza A, Giuliani R. Cardiorespiratory effects of positive end-expiratory pressure during progressive tidal volume reduction (permissive hypercapnia) in patients with acute respiratory distress syndrome. Anesthesiology 1995; 83: 710-720.

94. Hickling KG. The pressure-volume curve is greatly modified by recruitment. A mathematical model of ARDS lungs. Am J Respir Crit Care Med 1998; 158: 194-202.

95. Jonson B, Richard JC, Straus C, Mancebo J, Lemaire F, Brochard L. Pressure-volume curves and compliance in acute lung injury: evidence of recruitment above the lower inflection point. Am J Respir Crit Care Med 1999; 159: 11721178 .

96. Martin-Lefèvre L, Ricard J-D, Roupie E, Dreyfuss D, Saumon G. Significance of the changes in the respiratory system pressure-volume curve during acute lung injury in rats. Am J Respir Crit Care Med 2001; 164: 627-632.

97. Gibson GJ, Pride NB. Pulmonary mechanics in fibrosing alveolitis: the effects of lung shrinkage. Am Rev Respir Dis 1977; 116: 637-647.

98. Mead J, Takishima T, Leith D. Stress distribution in lungs: a model of pulmonary elasticity. J Appl Physiol 1970; 28: 596608.

99. Dreyfuss D, Saumon G. Evidence-based medicine or fuzzy logic: what is best for ARDS management? Intensive Care Med 2002; 28: 230-234. 